\title{
Introduction of new professional standards in the education system of fire and rescue units of the ministry of emergency situations of Russia
}

\author{
D.V. Totsky ${ }^{1 *}, A . S$. Davidenko ${ }^{2}, V . A$. Borisova ${ }^{2}$, and K.A. Novozhilova ${ }^{3}$ \\ ${ }^{1}$ Don State Technical University, 344002, Rostov-on-Don, Russian Federation \\ ${ }^{2}$ St. Petersburg State University of State Fire Service of the Ministry of Emergency Situations of \\ Russia, St. Petersburg, 196105, Russian Federation \\ ${ }^{3}$ Ivanovo Fire Rescue Academy of the Ministry of Emergency Situations of Russia, 153040, Russian \\ Federation
}

\begin{abstract}
An analysis was made of the current requirements for the training of fire and technical experts and external pilots of the emergency and disaster response system. By the example of training forensic experts of forensic institutions and expert subdivisions of the Federal Fire-Fighting Service of the State Fire-Fighting Service (fire extinguisher expert) the introduction of new professional standards into the educational system of this specialty was examined, on the basis of which the recommendations for modifying the educational program, in order to increase the quality of fire place examination were proposed. When extending the training program of the firefighting expert in the field of external piloting training, the trainee will additionally master professional competences in control and maintenance of unmanned aerial systems. Supplementing the training program for specialists of judicial-expert and expert subdivisions of the Federal Fire-Fighting Service of the State Fire-Fighting Service with labor functions in flight operation of unmanned aircraft systems, including one or more unmanned aircrafts, will allow the graduate of the educational organization to be awarded the qualification "External pilot", which, in turn, will also improve the quality of the above-mentioned subdivisions.
\end{abstract}

\section{Introduction}

Every day in the world, new discoveries are made, new systems are published, techniques and algorithms in human life are improved.

In order to obtain the necessary information today, the techniques and methods of obtaining it are being actively improved, introducing new channels of communication and technical means. Reliable information plays a key role in many aspects of our life, including in the work of specialists of forensic and expert divisions of the federal fire service of the State Fire Service (FED FFS SFS) [1].

The purpose of this work is to improve the system of training of external pilots of the personnel of FED FFS SFS, aimed at acquiring new competencies and the formation of

\footnotetext{
* Corresponding author: 9158384777@mail.ru
} 
skills in the management of modern technical means. To achieve the goal, the following specific tasks were solved: the tasks of unmanned aircraft systems (UAS) used for the purposes of the Ministry of Emergency Situations of Russia were investigated; new approaches to training external pilots, taking into account the capabilities of UAS and the tasks of the Ministry of Emergency Situations of Russia were proposed.

\section{Objectives of fire technical expertise and competencies of experts}

Fire technical expertise is a separate area from all other types of forensic examinations. It belongs to the engineering and technical category, so it differs from the other types by the subject of the examination. The latter is the actual data on such indicators as: causes, conditions, circumstances that influenced the occurrence of fire, its development and consequences [2]. To the questions of the subject of fire-technical examination include the exact location of the seat of fire, the nature of the spread of fire and smoke, its ways and routes, the exact time of the beginning and its duration of burning, as well as many other nuances [3-6].

To carry out fire-technical expertise, such specialists as fire-technical experts (FTE) are involved, who must have special qualifications, the presence of certain knowledge, skills and abilities. Preparation of PTE provides the implementation of the basic vocational training program of higher education - the program of a specialist on specialty 40.05 .03 Forensic Activity (training program), where as obligatory is a type of professional activity jurisprudence. As a result of mastering the above-mentioned training program a student acquires the specialty "Forensic Science", allowing him to work as a PTE. This specialty is provided by the labor functions:

- forensic support of the preliminary investigation (preliminary investigation) of crimes;

- performance of certain functions of procedural control;

- additional professional training of employees engaged in the investigation and detection of crimes.

\section{Unmanned aerial systems in the work of the fire expert}

The analysis of the completeness of specialized technical means (devices and equipment) for work of PTE at the place of fire showed that the specialist of this branch should have an unmanned aerial system of helicopter type. This system, equipped with a photo-video camera and a TV set allows carrying out fixing of the information in a zone of fire during its inspection [7]. Thus, it has been established that the FED FFS SFS, being under the jurisdiction of the Ministry of Emergency Situations of Russia, is not provided with competent specialists, who could improve the inspection of the place of fire with the use of UAS and improve the quality of their work.

It is worth considering that in order to ensure civil defense, protection of population and territories from emergencies of natural and technogenic character, including to ensure the safety of people on water bodies and fire safety, state special-purpose aviation is used. In addition, the use of aviation complexes designed to perform the functions and tasks assigned to the Ministry of Emergency Situations of Russia, according to the Air Code of the Russian Federation, is one of the top government priorities in the use of airspace.

Today in the subdivisions of the Ministry of Emergency Situations of Russia, actively implemented and used UAS, which are represented by different principles of operation, forms, sizes, payload and purpose [8]. In the FED FFS SFS, an effective way to solve a wide range of tasks, including in the form of observation, is the use of UAS, as well as 
various kinds of software applications for processing the obtained photo- and/or video information from digital photo and (or) video cameras, thermal imagers installed on them [9].

The authors believe that for full-fledged application of UAS the operator of PTE, controlling it (external pilot), must possess the relevant competences, which should be acquired during mastering the training program. Here it is noted that the requirements of Russian federal educational standards provide only full-time education in this specialty and cannot include e-learning training, which coincides with the training of UAS external pilots, having no foreign analogues $[10,11]$.

\section{Training of unmanned aerial systems operators}

The world experience of using and operating unmanned aerial vehicles in various fields points to the undeniable advantages of operating aerial systems with external piloting, but the human factor plays a huge role, on which the efficiency and safety of unmanned systems operation depends in the first place. It is worth noting that the operator and the aircraft he controls are separated in space, which forms a number of obstacles to optimal performance of control tasks on the part of the human operator. Such obstacles include sensory information, delays and interruptions in control loop communication lines, heterogeneity of activity tempo intensity [12].

Presenting uniform qualification requirements for operators of unmanned aerial systems and externally piloted aircraft. Among such necessary minimum requirements to the content of knowledge, skills and abilities of specialists can be included:

- mandatory knowledge of aerodynamic fundamentals, fundamentals of meteorology, as well as such issues as the organization of air navigation, safety of organizing and conducting flights of unmanned aerial vehicles with external aerobatics;

- theoretical knowledge of the components of unmanned aircraft systems, including drones, as well as the rules of their operation and maintenance;

- mastering the tactics of using unmanned aircraft systems;

- the ability to carry out practical actions aimed at planning the use of an unmanned aerial vehicle, its preparation for flight, control of the vehicle, post-flight maintenance of the complex and its elements, within the framework of certain functional duties.

It is possible to achieve a full mastery of the external pilot specialty by acquiring the above mentioned knowledge and skills. This is possible through a rational combination of theoretical training, practical training on UAS simulators, as well as independent performance of flights by trainee operators under the guidance of an instructor [13].

Currently, the most rational and effective way to train an unmanned aerial vehicle operator and a specialist in information processing and control of unmanned aerial vehicles, as well as to develop the skill of handling unmanned aerial vehicles is to use automated training systems (ATS). These systems are designed to teach and train operators to perform specific functional tasks using UAS.

\section{Suggestions and points for discussion}

State special-purpose aviation of EMERCOM of Russia in achieving its goals through the Department of Aviation and Aviation Rescue Technologies of EMERCOM of Russia solves private tasks: inspection of inaccessible areas of the border, observation of various land and water surfaces, determining the consequences of natural disasters and accidents, identifying forest fires, performing search and other activities. 
To solve these problems it is proposed to integrate the training program of the external pilot of EMERCOM of Russia into the training program of PTE and consider the introduction of the professional standard "Specialist in the operation of UAS, including one or more unmanned aerial vehicles with a maximum take-off weight of $30 \mathrm{~kg}$ or less" within the mandatory discipline "Forensic photography and video recording" (Block B of the general labor function of the standard). This order is proposed to implement on the principle of mastering the training programs of specialists of secondary level, who should master one or more professions of a worker in the process of training. According to the authors, the training program of PTE - external pilot of EMERCOM of Russia should contain a theoretical block (Figure 1), which reflects the main issues of airspace use and responsibility for its use. The issues of compulsory insurance of the UAS and safety of its operation, responsibilities of crews and officials, as well as the organization of the use of the UAS should also be considered.

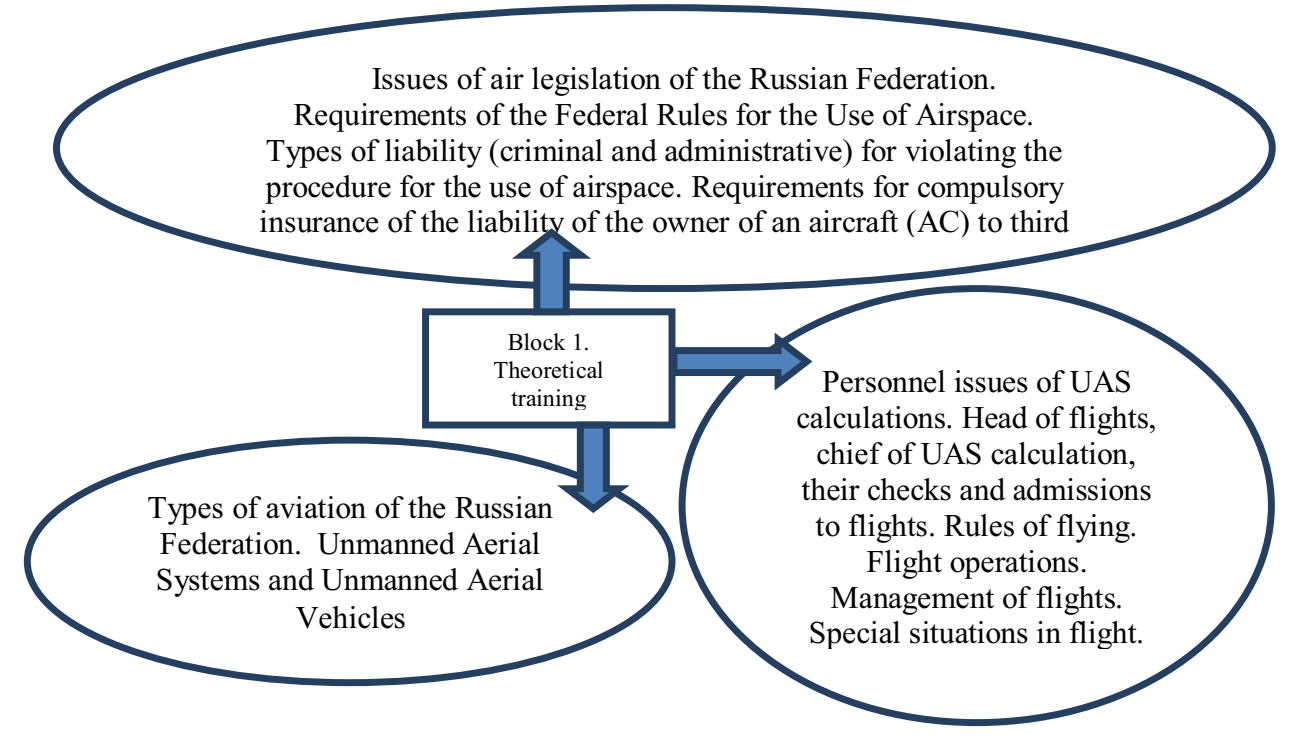

Fig. 1.Suggestions for the theoretical block.

Block 2 of the program provides the practical part of the PTE training - external pilot of the Russian EMERCOM (Fig. 2) and provides for the study of the basic design characteristics of the UAS, its software and life support systems. Also, it is supposed to practice taking off, landing, maneuvering along different trajectories, as well as controlling the UAS in emergency situations. Exercises of training flights of the practical block were formulated taking into account the requirements for conducting an inspection of the place of fire of the PTE.

Today, the training procedure for external pilots of EMERCOM of Russia implies training in a departmental educational organization under the program of additional professional education (APE) - professional retraining program under the state assignment at the Academy of Civil Defense of EMERCOM of Russia (Figure 3). Such an order is quite different from the foreign experience, where the external pilot of UAS provides several types of training levels for one or another type of activity [14, 15].Thus, if it is necessary to assign the qualification "external pilot" to the employee of EMERCOM of Russia, it is necessary to spend additional time for mastering the program of additional professional education, the employer should provide and plan the budgetary allocations for training of the employee, including travel expenses, as well as take into account the separation of the employee from the main type of activity. It is also necessary to take into 
account the territorial factor, which burdens the financial component and the time parameter in the full-time mastering of the above APE program.

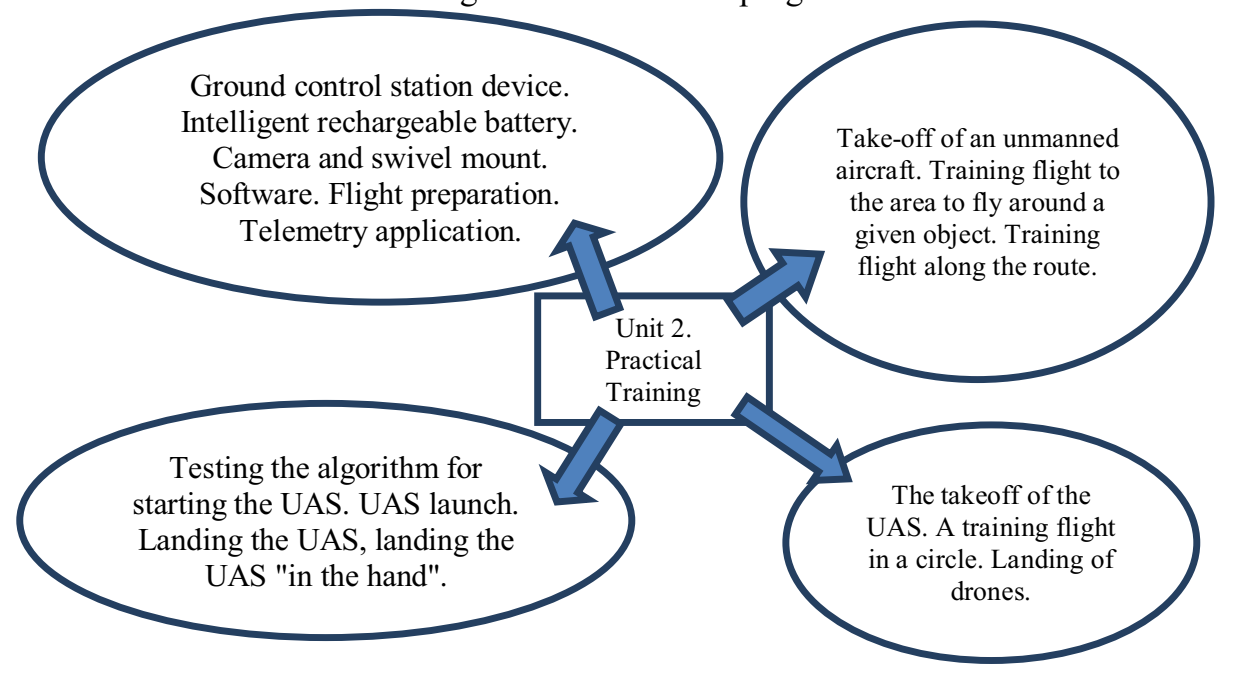

Fig. 2. Suggestions for the practical block.

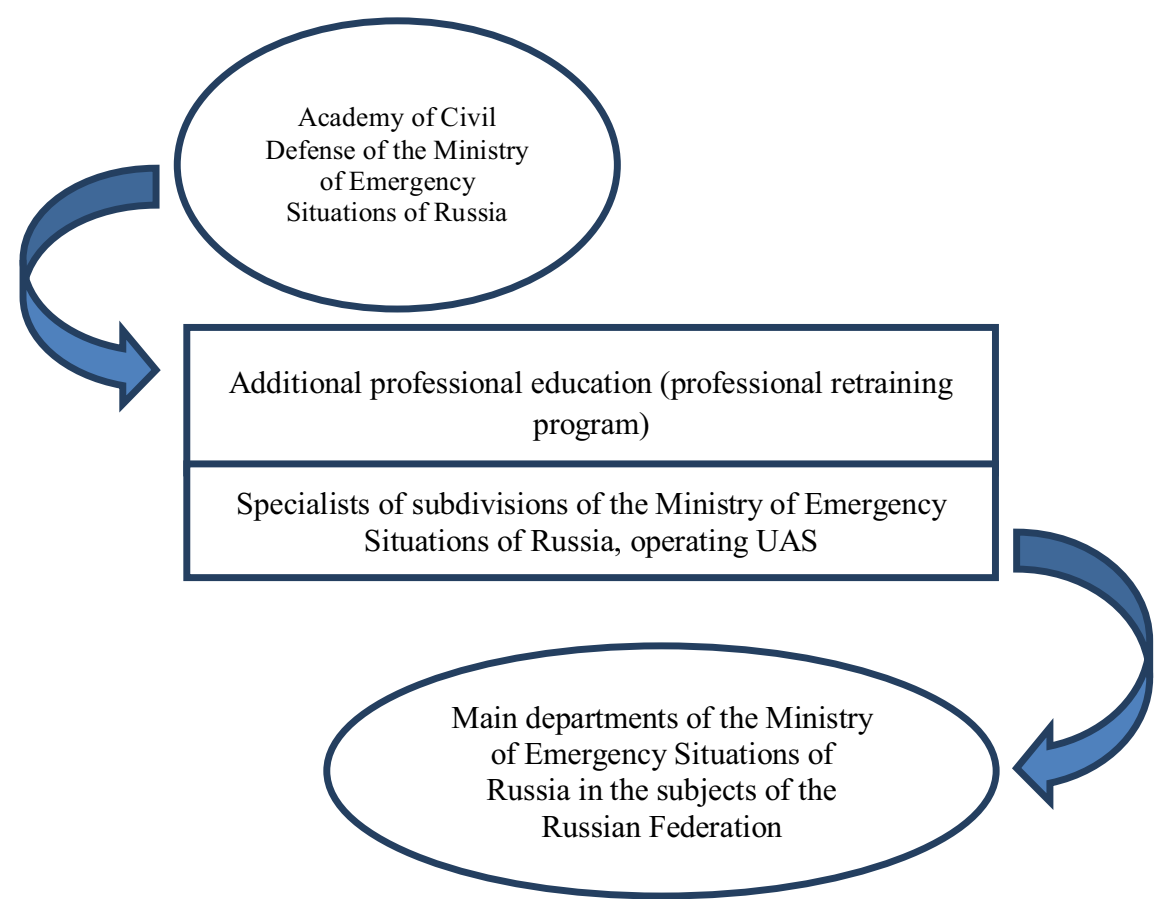

Fig. 3. Interaction between departments to train UAS specialists for the Russian Ministry of Emergency Situations system

\section{Discussion}

It should be noted that a graduate of an educational organization of the Russian Ministry of Emergency Situations with a specialization in "Forensic Expertise" with the qualification of 
an external pilot of the UAS will be more demanded by the employer as having additional competences in working with the technical means of FED FFS SFS. In this case, the head of the unit will not need to send the newly arrived employee for further training and retraining for the right to control the UAS.

The result of training PTE - external UAS pilots proposed to pass a comprehensive exam, which will consist of theoretical and practical part, where the trainee must demonstrate:

- ability to organize and carry out the pre-flight preparation and operation of the UAS when inspecting the place of fire;

- ability to interact with air traffic control services when using airspace;

- ability to process information obtained when using UAS;

- ability to keep records of the performance of the main UAS systems, the causes of their failures, malfunctions and damage;

- ability to maintain unmanned aerial vehicle payload equipment in serviceable condition;

- skills in setting up, adjusting, adjusting and testing all UAS systems in laboratory conditions;

- -skill in maintaining operational and technical documentation.

\section{Conclusions}

As a result of the conducted work the normative-legal base in the field of education concerning the training of PTE and external UAS pilots, the availability of modern technical systems in service of subdivisions of the Ministry of Emergency Situations of Russia was analyzed, recommendations for improving the training of experts of FED FFS SPS, allowing to improve the quality of work on inspection of the fire scene were proposed.

Thus, supplementing the training program of FED FFS SPSspecialists with the labor functions on the flight operation of the UAS, including one or more UAS, as well as excluding electronic training [16], will allow to assign the qualification of "external pilot" to the graduate of the educational organization of the Russian EMERCOM, which will ensure the full performance of tasks, facing the Russian EMERCOM.

\section{References}

1. A.M. Kustov, K.E. Shimanovskaya, Advances in Chemistry and Chemical Technology 30 (5) (174), 40-42 (2016).

2. Bernard J. Scheiner, C. E. Jordan, J. M. Kuchta, Karl C. Dean, Martin H. Stanczyk, Maurice Deul, Paulette B. Altringer, William C. McBee, Ann G. Kim, Annie G. Smelley, Lawrence J. Froisland, R. S. DeCesare, G. V. Sullivan, Donald A. Stanley, M. B. Shirts, Thomas A. Sullivan, Harold L. Fike, A Manual 678-688, U.S. Department of the Interior, Bureau of Mines, 1985.

3. Scientific Protocols for Fire Investigation, Third Edition, John J. Lentini, CRC Press, 28 of September, 2018.

4. F.M. Williams-Bell, B. Kapralos, A. Hogue, et al., Fire Technol 51, 553-584 (2015). https://doi.org/10.1007/s10694-014-0398-1.

5. E.V. Muravyeva, M.V. Golovko, S.R. Yusupov, R.G. Biktemirova, G.V. Morozova, T.T. Sidelnikova, Asian Social Science 11 (1), 142-147 (2015). URL: http://dx.doi.org/10.5539/ass.v11n1p142. 
6. Gobert Thierry, Recherche \& formation 82, 61-74| (2016). DOI: 10.4000/rechercheformation.2667. URL: https://www.cairn-int.info/journal-rechercheet-formation-2016-2-page-61.htm.

7. A.S. Davidenko, A.A. Rodionov, Application of unmanned aerial systems in the interests offire protection, Proceedings of the VII International Scientific and Practical Conference "Fire fighting: problems, technologies, innovations" in 2 parts, 2 Moscow: Academy of State Fire Service of Emergencies Ministry of Russia, 2020.

8. A.E. Kishalov, R.R. Galimzyanova, Youth Bulletin of UGATU, Monthly magazine Monthly magazine 1 (13), 74-79 (2015).

9. E.A. Lappo, Bulletin of the Ural Law Institute of the Ministry of Internal Affairs of Russia 4, 79-82 (2019).

10. Waqas Sultani, Mubarak Shah, Computer Vision and Image Understanding, 103186, ISSN 1077-3142 (2021). https://doi.org/10.1016/j.cviu.2021.103186.

11. O. Fontaine, A. Martinetti, S. Michaelides Mateou, Chemical Engineering Transactions 53, 205-210 (2016).

12. D. Doroftei, G. De Cubber, H. De Smet, Reducing Drone Incidents by Incorporating Human Factors in the Drone and Drone Pilot Accreditation Process, Zallio M. (eds) Advances in Human Factors in Robots, Drones and Unmanned Systems. AHFE 2020. Advances in Intelligent Systems and Computing, Springer 1210 (2021). https://doi.org/10.1007/978-3-030-51758-8_10.

13. K.A. Zlotnikov, A.A. Volosyuk, H.A. Tan, Proceedings of the Second International Scientific and Practical Conference, St. Petersburg, 2016.

14. O. Islamova, V. Hrishko-Dunaievska, O. Biliovskyi, O. Kulagin, O. Hnydiuk, V. Miroshnichenko, Revista Inclusiones 8, 556-570 (2021).

15. D. Thirtyacre, C. Woodyard, Scholarly Commons Citation, Small Unmanned Aircraft Systems Flight Training Programs Through the Lens of a Traditional Flight Training University. (2018). [URL: https://commons.erau.edu/publication/1511].

16. D.C. Niehorster, M. Hildebrandt, A. Smoker, H. Jarodzka, N. Dahlström, Towards eye tracking as a support tool for pilot training and assessment, Eye-Tracking in Aviation. Proceedings of the 1st International Workshop (ETAVI 2020). https://doi.org/10.3929/ethz-b-000407610. 